\title{
World Family Portrait: \\ A celebration of humanity's place in the world
}

RISC Consortium

In 2014, the Regional Integration and Social Cohesion (RISC) Consortium launched an ongoing interactive initiative entitled A World Family Portrait. This call for contributions invites scholars, practitioners, journalists, photographers, and so forth, to submit written and photographic contributions in English, French or Spanish that provoke a contemporary reflection on the human condition through the presentation and analysis of life challenges and opportunities. The goal of these publications is not simply to document world events/social conditions but also to engage readers through photography and prose in a dialogue focusing on the evolution of our world and humanity's place in it.

Selected photos will be published periodically in the Leadership Forum section of Regions \& Cohesion. Interested contributors should go to the "World Family Portrait" link at www.risc.lu where texts and photographs can be uploaded along with basic information, such as author name(s), correspondence address, institutional affiliation, and current position. Articles should be approximately 500 words in length. Images should be submitted in JPEG format at a resolution, at this stage, of approximately 1900x1600 pixels. All materials must be original. 


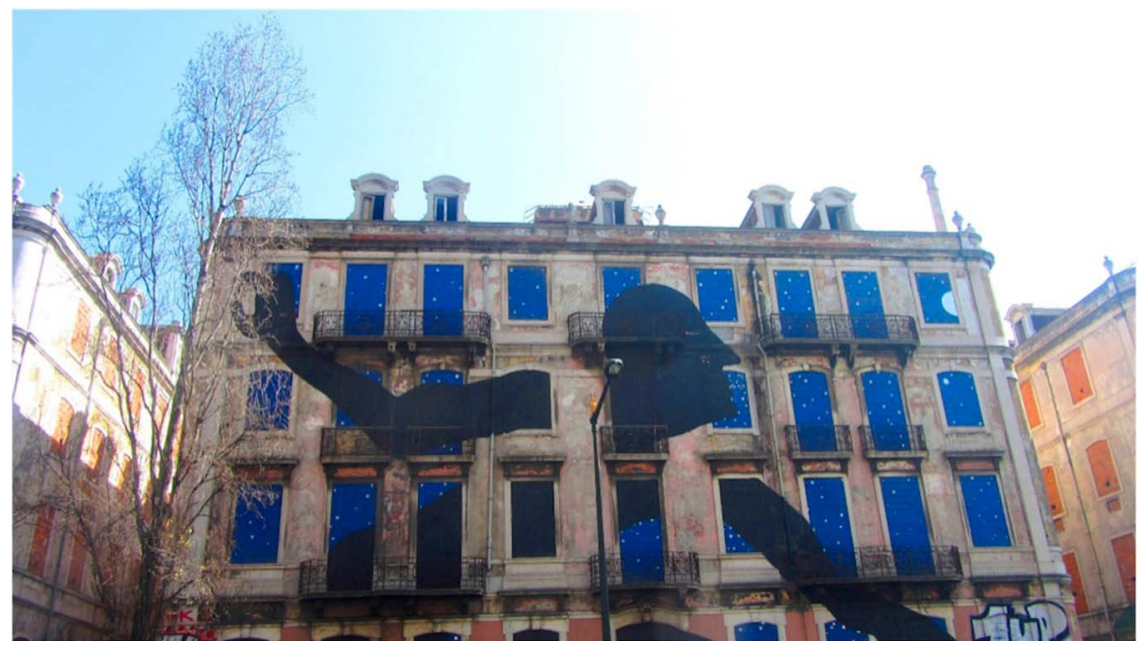

Figure 1 - The Teeming Void by Cristina Blanco Sío-López

This empty house in post-economic crisis Lisbon is occupied by artists devoted to filling it with an overflowing hope for a more inclusive and cohesive society capable of rebuilding itself through solidarity.

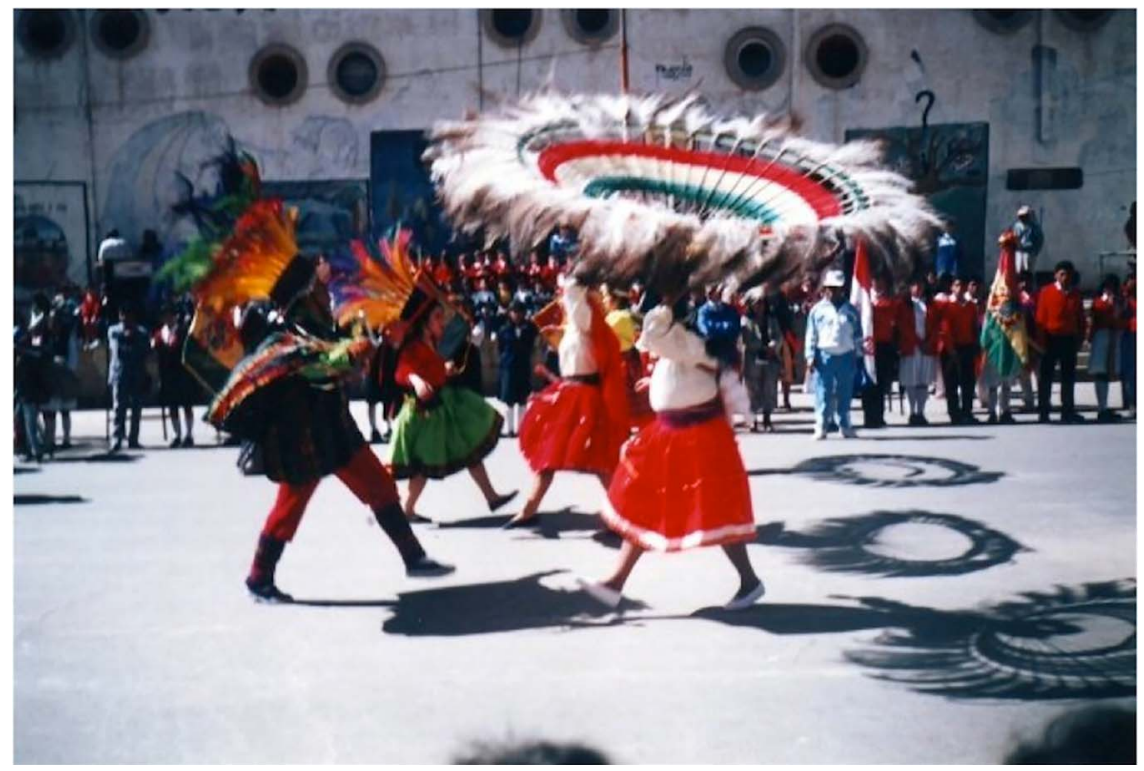

Figure 2 - Caressing the Ground by Cristina Blanco Sío-López

This flying caress on the ground by the Bolivian indigenous communities in Oruro traces seeds of sustainability beyond their tangible shadows. In affirming their diversity, they give wings to the future. 


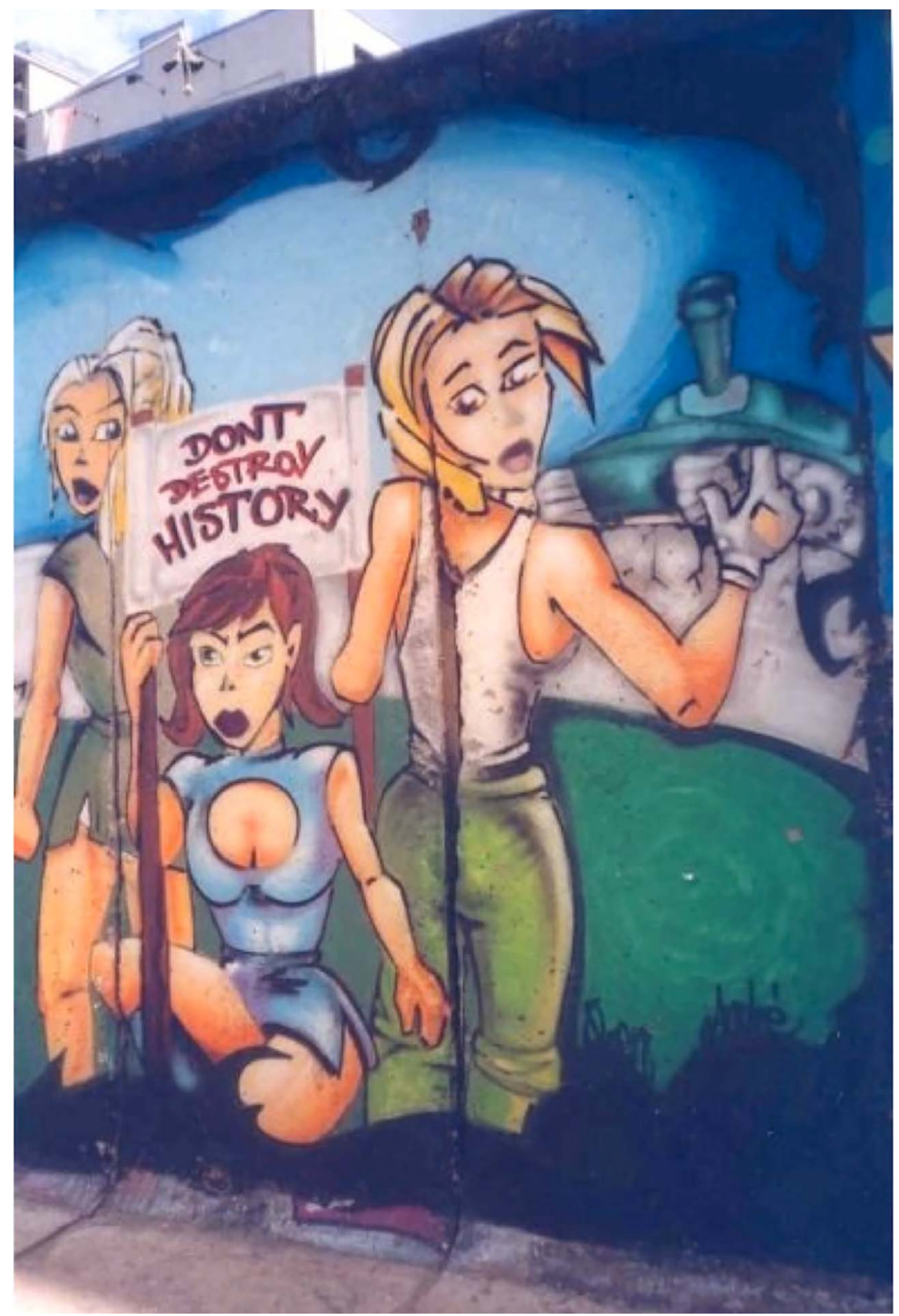

Figure 3 - The Edge of Time by Cristina Blanco Sío-López

This now-destroyed remainder of the Berlin Wall was painted by local activists as a reminder of the semantic charge and value of critical memory as a force capable of transforming former frontiers of risk and conflict into bridges of cooperation and future-oriented society building. 